Maatouk Khoukhi, 2021

Volume 5 Issue 2, pp. 33-43

Received: 08th April 2021

Revised: 17 th July 2021; 24 $4^{\text {th }}$ July 2021

Accepted: 23rd August 2021

Date of Publication: 03rd September 2021

DOI- https://doi.org/10.20319/pijtel.2021.52.3343

This paper can be cited as: Khoukhi, M. (2021). Assessment of General Engineering Courses in the UAE University and Recommendation Actions for Improvement. PUPIL: International Journal of Teaching, Education and Learning, 5 (2), 33-43.

This work is licensed under the Creative Commons Attribution-NonCommercial 4.0 International License. To view a copy of this license, visit http://creativecommons.org/licenses/by-nc/4.0/ or send a letter to Creative Commons, PO Box 1866, Mountain View, CA 94042, USA.

\title{
ASSESSMENT OF GENERAL ENGINEERING COURSES IN THE UAE UNIVERSITY AND RECOMMENDATION ACTIONS FOR IMPROVEMENT
}

\author{
Maatouk Khoukhi \\ College of Engineering, United Arab Emirates University, Al Ain, UAE \\ mkhoukhi@uaeu.ac.ae
}

\begin{abstract}
The current study examined the Architectural Engineering (AE) students at the College of Engineering (COE) at United Arab Emirates University (UAEU) learning outcomes through assessing three main engineering requirement courses. The assessment is based on the direct method which consists of the achievement of the students and their capability to demonstrate mastery through actual work or work products such as presenting the facts. The CLOs have been assessed through Course Work (Quizzes, Home works, and Term Projects) and Examinations (Midterm and Final Exams). The course learning outcomes (CLOs) for each course for the AE program have been analyzed in terms of the level of achievement and compared with the overall achievements of all students enrolled in the same courses at the COE. This assessment has been carried out for three continuous semesters fall 2019, spring 2020, and fall 2020. Indeed, some deficiencies in terms of CLOs achievement which has been set below $70 \%$ are recorded and remedial actions have been
\end{abstract}


provided for improvement. The second part of this study consists of the comparison of the attainment level of the CLOs of GENG215 course between two consecutive semesters fall 2019 and spring 2020. Indeed, this period was characterized by the drastic change in the teaching method moving from the traditional way of face-to-face interaction with students to online teaching.

\section{Keywords}

General Engineering Courses, Architectural Engineering Program, Course Assessment, ABET, CLO

\section{Introduction}

Different college programs are assessing and monitoring students learning outcomes by implementing several assessment tools across multiple levels within their institutions (Banta, 2004). However, the nature of these assessments has shifted in recent years from assessing faculty teaching to demonstrating student learning (Martell, 2007). Increasingly, institutions of higher education are being challenged by their accrediting agencies (Martell, 2007) and legislative entities (Fort, 2011) to not only provide evidence of the investment of resources and offering of programs for various learning initiatives but to also demonstrate actual student learning and the achievement of specific program learning outcomes (Luce \& Kirman, 2016). Two major methods of courses assessment are being used by academic institutions which are direct and indirect methods. Direct methods of courses assessment demonstrate mastery through exams and assignments for instance. Indirect measures, reflect opinions and are obtained from surveys and interviews (Price \& Randall, 2008).

The college of engineering (COE) is one among height other colleges in United Arab Emirates University (UAEU) (Colleges of United Arab Emirates University, 2021). The COE was inaugurated in 1980 and includes five academic departments that offer seven Bachelor degrees, namely Architectural Engineering, Chemical Engineering, Civil Engineering, Communication Engineering, Electrical Engineering, Mechanical Engineering, and Petroleum Engineering, all of which are recognized nationally by the Ministry of Higher Education and Scientific Research. In addition, all undergraduate programs in the COE are accredited by the Engineering Accreditation Commission of Accreditation Board for Engineering and Technology (ABET, 2021) and (COE, 2018).

The Center for Excellence in Teaching \& Learning (CETL) supports the UAEU's strategic vision and mission by promoting emerging educational technologies and assessing and measuring 


\section{PUPIL: International Journal of Teaching, Education and Learning ISSN 2457-0648}

teaching effectiveness and efficiency as well. All courses taught at COE are subjected each semester to direct and indirect assessment.

The Engineering Requirement Unit (ERU) provides students with a solid foundation in basic science, mathematics, and general engineering fundamentals. Moreover, the unit offers the general fundamental engineering courses that are needed for all COE students including Engineering Ethics (GENG215), Engineering Thermodynamics (GENG220), and Engineering Economics (GENG315) (Engineering Requirement Unit, 2020).

Furthermore, several researchers have recently identified concerns regarding student motivation when taking standardized measures constructed for assessment purposes (Huffman, Adamapoulos, Merdock, Cole, and McDermid, 2011; Liu, Bridgeman, and Adler, 2012). The "high stakes" for an institution or department contrast with the "low stakes" for the student, and research has shown that a lack of motivation on the part of respondents may influence the validity of these measures as well as the conclusions drawn regarding student learning. Huffman et al. (2011) demonstrated higher scores on the Psychology Area Concentration Achievement Test (a major fields test) when students were provided with a statement on the importance to the department of honest and effortful responses. Liu et al. (2012) found similar results for the ETS Proficiency Profile where higher scores were achieved when an institutional or personal motivation condition was present. These researchers collectively resolved that assessment without proper respondent motivation can lead to erroneous conclusions (Luce \& Kirman, 2016).

As mentioned above this study will focus on the direct measures of learning which demonstrate a master of knowledge rather than an opinion about one's ability. There are several methods of direct measurement as described by (Luce \& Kirman, 2016) which include tests, papers, projects, and presentations. This direct method administered through the whole semester will identify the increased knowledge gained by the students from the start to the end of the course (Pederson \& White, 2011). Several researchers highlighted the importance to clarify what we want students to learn from the assignments and the build and design the assignments that will help them achieve those goals (Banta \&Palomba, 2015; Suskie, 2009).

The target of this paper is to highlight the assessment of the GENG215, GENG220, and GENG315 taken by AE students and compare them with COE students, and provide the recommended actions for improvement during the last three semesters. The impact of online teaching students' performance was also analyzed for GENG215 and the most affected CLO was highlighted. 


\section{Methodology}

The target population for this study consists of undergraduate students in COE at UAEU. Three courses have been considered in this study which are college requirement courses taken by all students enrolled in the COE. The courses are Engineering Ethics with course code GENG 215, Engineering Thermodynamics with course code GENG 220, and Engineering Economics with course code GENG 315. The GENG 215 teaches a set of moral and ethical principles that relate to Engineering projects and designs. The course explores creative ways of reconciling conflicting moral and ethical claims. It outlines the responsibilities of engineers towards public safety and the environment, within economic constraints and governing laws. The GENG 220 deals with the basic thermo-physical properties of pure substances and gases with the introduction to the first law of thermodynamics, conservation of energy, and closed and open systems. The second law of thermodynamics and entropy are also introduced in this course. The GENG 315 is related to the basic concepts and principles of engineering economics. Familiarization of the different cost components, cost estimation techniques, cash flow analysis, time value of money, and measures of project performance. [https://eng.uaeu.ac.ae/en/departments/eru/courses.shtml]

Each course learning outcome CLO is analyzed using a developed excel sheet and direct and indirect results are reported for each section taught for the considered courses. The attainment target is reached for $70 \%$ of enrolled students with a score of $70 \%$ or higher in summative assessment tools obtained in the course work and exams. Table 1 contains the CLOs for each considered course. This assessment is done through the Learning Outcomes Assessment Management System (LOAMS) at UAEU. The assessment report obtained for each course contains the following points:

- The CLO attainment results and analysis remarks

- General comments on any problems encountered with the course

- Recommendations

- Implementation of recommendation actions. 
Table 1: Course Learning Outcomes for each Course

\begin{tabular}{|c|c|c|}
\hline Courses & CLO\# & CLO statement \\
\hline \multirow{6}{*}{ GENG215 } & 1 & $\begin{array}{l}\text { Identify ethical and professional issues pertaining to personal integrity, and } \\
\text { professional conduct pertaining to the society and the environment }\end{array}$ \\
\hline & 2 & $\begin{array}{l}\text { Recognize an engineering ethical dilemma and apply a systematic process } \\
\text { of moral and ethical reasoning to resolve it }\end{array}$ \\
\hline & 3 & $\begin{array}{l}\text { Analyse several moral theories and principles (e.g., utilitarianism, duty } \\
\text { ethics, virtue ethics, and religious ethics) and apply them to the examination } \\
\text { of ethical issues in engineering }\end{array}$ \\
\hline & 4 & $\begin{array}{l}\text { Analyse case studies of conflict in Engineering and make choices based on } \\
\text { engineering ethics codes and apply one to the resolution of an ethical } \\
\text { dilemma }\end{array}$ \\
\hline & 5 & $\begin{array}{l}\text { Identify the value of teamwork and multi-discipline work in relation to types } \\
\text { and scales of projects through assignments and group projects }\end{array}$ \\
\hline & 6 & $\begin{array}{l}\text { Apply the design process using systematic design methods and identify the } \\
\text { related professional responsibilities and ethical issues }\end{array}$ \\
\hline \multirow{7}{*}{ GENG220 } & 1 & Explain the basic concepts of macroscopic thermodynamics \\
\hline & 2 & Explain the properties of pure substances \\
\hline & 3 & $\begin{array}{l}\text { Explain the heat transfer and work interaction between a system and its } \\
\text { surroundings }\end{array}$ \\
\hline & 4 & Apply the first law of thermodynamics for closed and open systems \\
\hline & 5 & Explain and apply the Second law concepts \\
\hline & 6 & $\begin{array}{l}\text { Analyse thermodynamic processes and cycles within the conceptual } \\
\text { frameworks of the First and Second laws }\end{array}$ \\
\hline & 7 & $\begin{array}{l}\text { Use the Engineering Equation Solver (EES) learning tool to solve } \\
\text { thermodynamics problems }\end{array}$ \\
\hline \multirow[b]{2}{*}{ GENG315 } & 1 & $\begin{array}{l}\text { Explain the principles of engineering economy and the engineering } \\
\text { economic analysis procedure }\end{array}$ \\
\hline & 2 & $\begin{array}{l}\text { Describe some of the basic cost terminology and concepts used in } \\
\text { engineering practice }\end{array}$ \\
\hline
\end{tabular}




\begin{tabular}{|l|l|l|}
\hline & 3 & Explain the concept of price demand relationship \\
\cline { 2 - 3 } & 4 & Describe the different techniques used for cost estimation \\
\cline { 2 - 3 } 5 & Explain the concept of the time value of money \\
\cline { 2 - 3 } & 6 & $\begin{array}{l}\text { Evaluate a single project and select among alternative project options } \\
\text { business plan }\end{array}$ \\
\hline 7 &
\end{tabular}

\section{Data Collection and Analysis}

Table 2 summarizes the learning outcomes for each ERU course taken by AE students which have been analyzed in terms of level of achievement and compared with the overall achievements at the college levels including all programs. Indeed, some of the CLOs for the GENG 215 and GENG 220 are below the attainment level (70\%) for the students enrolled in AE program. Although 69\% attainment is registered in CLO2 by AE students in fall 2019, the rest of the CLOs attainments are higher than the threshold and are comparable to the overall achievements at the college levels. The AE students' performance is below 70\% for CLOs 3 and 5 in GENG 220 which are related to the knowledge of heat transfer and the second law concept, respectively. On the other hand, the overall students at the COE registered low attainments for the both same CLOs which could have been explained either by the complexity of the assessments tools related to the CLOs or by the nonadequacy of the tools used to assess these CLOs. In the same course, low attainments are registered in three CLOs by the AE students in fall 2020. The attainment levels are 62, 62, and 65 for CLO1, CLO3, and CLO4, respectively. One of the main reasons for such drawbacks in the attainment levels of the three CLOs is due to the online classes offered in fall 2020 which represent a challenge for both instructors and students. Indeed, the students and instructors were not that prepared to tackle different situations, opportunities, and problems associated with the online scenario.

Table 2: Level of achievement of CLOs for each ERU course

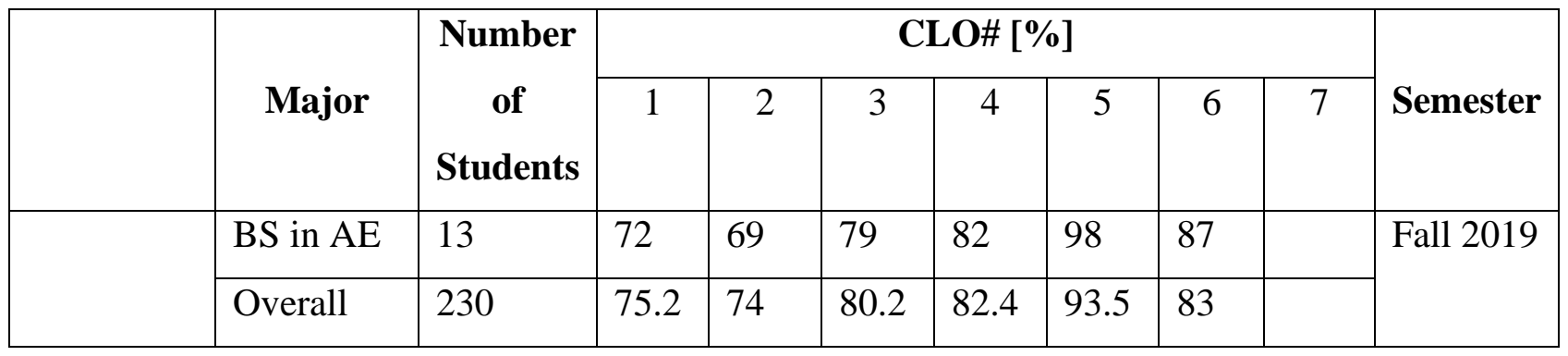




\begin{tabular}{|c|c|c|c|c|c|c|c|c|c|c|}
\hline \multirow{4}{*}{ GENG215 } & $\mathrm{BS}$ in $\mathrm{AE}$ & 12 & 80 & 80 & 85 & 78 & 95 & 70 & & \multirow{2}{*}{$\begin{array}{l}\text { Spring } \\
2020\end{array}$} \\
\hline & Overall & 211 & 78 & 79 & 83 & 79 & 92 & 79 & & \\
\hline & $\mathrm{BS}$ in $\mathrm{AE}$ & 17 & 86 & 84 & 89 & 80 & 85 & 90 & & \multirow[t]{2}{*}{ Fall 2020} \\
\hline & Overall & 256 & 81.7 & 84 & 82.8 & 82.5 & 87.8 & 86.3 & & \\
\hline \multirow{6}{*}{ GENG220 } & $\mathrm{BS}$ in $\mathrm{AE}$ & 28 & 85 & 82 & 69 & 77 & 58 & 79 & 93 & \multirow[t]{2}{*}{ Fall 2019} \\
\hline & Overall & 296 & 80 & 81.4 & 62.8 & 73.8 & 67.3 & 72.8 & 89.3 & \\
\hline & $\mathrm{BS}$ in $\mathrm{AE}$ & 13 & 62 & 74 & 62 & 65 & 85 & 75 & 92 & \multirow{2}{*}{$\begin{array}{l}\text { Spring } \\
2020\end{array}$} \\
\hline & Overall & 182 & 74 & 82 & 73 & 79 & 82 & 78 & 91 & \\
\hline & $\mathrm{BS}$ in $\mathrm{AE}$ & 28 & 79 & 80 & 79 & 70 & 87 & 80 & 90 & \multirow[t]{2}{*}{ Fall 2020} \\
\hline & Overall & 218 & 79.1 & 80.5 & 73.2 & 75.2 & 90.8 & 85.1 & 89.2 & \\
\hline \multirow{6}{*}{ GENG315 } & $\mathrm{BS}$ in $\mathrm{AE}$ & 19 & 87 & 80 & 72 & 76 & 89 & 78 & 82 & \multirow[t]{2}{*}{ Fall 2019} \\
\hline & Overall & 229 & 85.5 & 76 & 79.6 & 75.9 & 87.9 & 79.1 & 78.2 & \\
\hline & $\mathrm{BS}$ in $\mathrm{AE}$ & 10 & 85 & 74 & 73 & 81 & 84 & 73 & 78 & \multirow{2}{*}{$\begin{array}{l}\text { Spring } \\
2020\end{array}$} \\
\hline & Overall & 161 & 76 & 76 & 88 & 78 & 83 & 80 & 78 & \\
\hline & $\mathrm{BS}$ in $\mathrm{AE}$ & 24 & 86 & 91 & 85 & 80 & 92 & 76 & 96 & \multirow[t]{2}{*}{ Fall 2020} \\
\hline & Overall & 237 & 85.4 & 87.4 & 86.3 & 79.4 & 88.6 & 78.1 & 90.3 & \\
\hline
\end{tabular}

The second part of this analysis is related to the comparison of CLOs attainments of one sample course for two consecutive semesters in fall 2019 and spring 2020 for all students in COE as shown in Table 3. The course sample considered for this analysis is GENG 215 and the number of sections with achievements lower than $70 \%$ for each CLO are reported for each considered semester and a list of recommendations has been set for remedial actions. We should mention to her that in fall 2019 seven sections have been assessed and in spring 2020 five sections have been assessed as shown in Tables 4 and 5 .

Table 3: CLOs Attainment of CE Students in the Three Courses

\begin{tabular}{|c|c|c|}
\hline \multirow{2}{*}{ CLOs } & \multicolumn{2}{|c|}{ Number of Section with Attainment $<$ 70\% } \\
\cline { 2 - 3 } & Fall 2019 & Spring 2020 \\
\hline 1 & 2 & 0 \\
\hline 2 & 1 & 0 \\
\hline 3 & 0 & 1 \\
\hline
\end{tabular}




\begin{tabular}{|l|l|l|}
\hline 4 & 1 & 2 \\
\hline 5 & 0 & 0 \\
\hline 6 & 0 & 2 \\
\hline
\end{tabular}

As a first observation on the results in Table 3, one can say that although the number of sections in spring was 5 five sections registered attainment lower than $70 \%$ during the online teaching. The most affected course learning outcome is CLO\#6 which deals mainly with the application of the design process. Due to the sudden decision taken by the UAE University administration to carry on the rest of spring 2020 from mid of March to the end of May using online teaching, the students and instructors were not that prepared to tackle different situations, opportunities, and problems associated with the online scenario. Higher-order thinking skills with a more detailed explanation of the design methods and their relation with the professional responsibilities and ethical issues by providing more assignments will be given more attention in the future.

Table 4: Sections with Number of Enrolled Students in Fall 2019

\begin{tabular}{|c|c|c|}
\hline SEC\# & Gender & Enrolment \\
\hline 01 & Male & 31 \\
\hline 02 & Male & 40 \\
\hline 51 & Female & 34 \\
\hline 52 & Female & 26 \\
\hline 53 & Female & 22 \\
\hline 54 & Female & 29 \\
\hline 55 & Female & 39 \\
\hline
\end{tabular}

Table 5: Sections with Number of Enrolled Students in Spring 2020

\begin{tabular}{|c|c|c|}
\hline SEC\# & Gender & Enrolment \\
\hline 1 & Male & 58 \\
\hline 2 & Male & 52 \\
\hline 3 & Male & 31 \\
\hline 51 & Female & 58 \\
\hline 52 & Female & 57 \\
\hline
\end{tabular}


The attainment levels of the six CLOs for GENG 215 for the two successive considered semesters are shown in Fig.1. Indeed, one can see as an average there are no significant discrepancies between the direct and indirect attainments for both semesters. However, the indirect attainment levels of CLO5 and CLO6 are not in line with the direct one for the spring 2021 semester. This could be attributed to the mixture of face-to-face and online teaching methods during the semester.

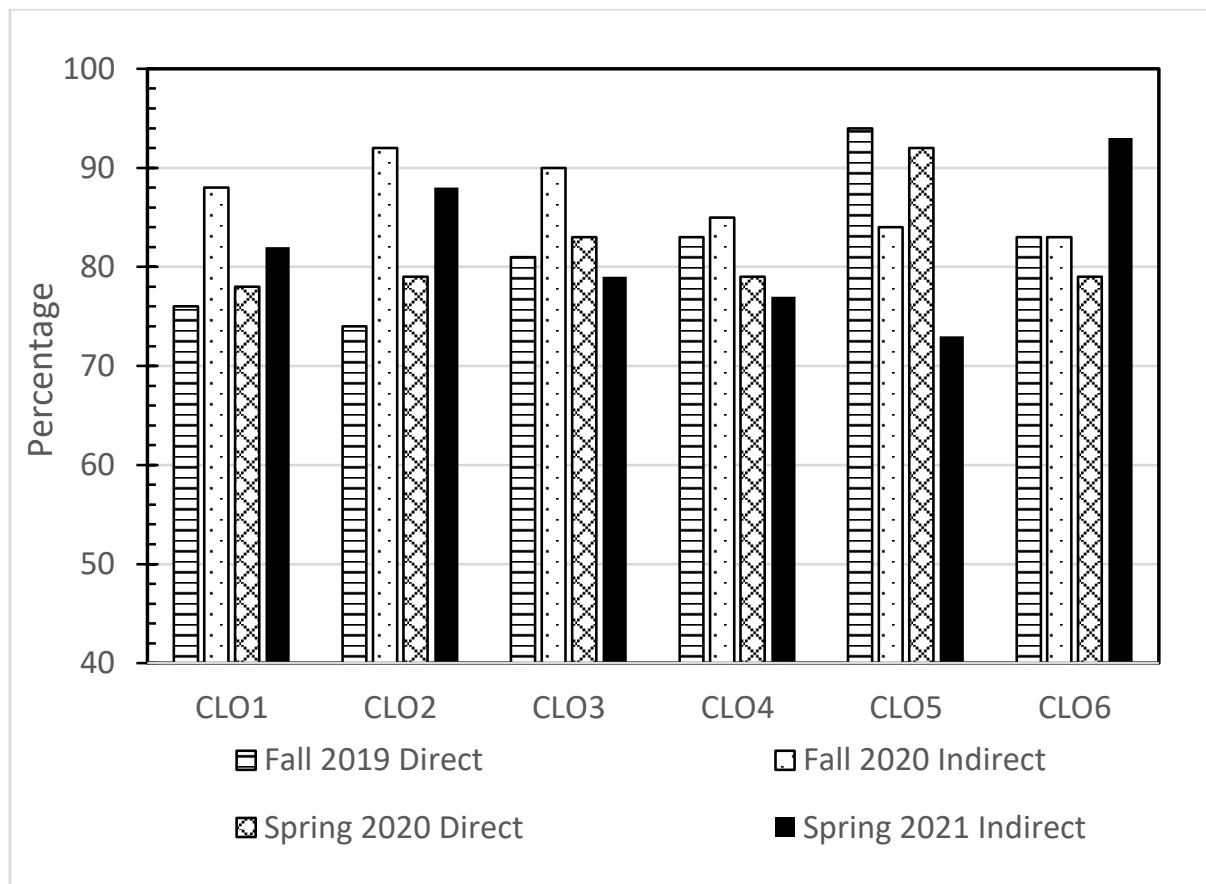

Figure 1: The GENG215 CLOs Attainment Levels for two Successive Semesters

\section{Conclusion}

The common engineering courses taught in COE at UAEU which includes GENG215 (Engineering Ethics), GENG220 (Thermodynamics), and GENG315 (Economics) have been assessed in terms of the level of attainment for each course CLOs for AE students and compared with all the students enrolled in COE. This study is summarized as follow:

- The CLOs of GENG 220 course are the most "negatively" impacted compared to GENG 215 and GENG 315. Indeed, the attainment of CLO3 and CLO5 is below 70\% in fall 2019, and CLO1, CLO3, and CLO5 are lower than the threshold in spring 2020. This could be explained by the nature of this course which deals mainly with physical phenomenon and theory of thermodynamics which require more interaction between student and instructor compared 
with the two other courses. This is not only applied to AE students but the same tendency is observed for all the students enrolled in COE particularly in fall 2019.

- Another reason for such drawback in the attainment levels of the three CLOs is due to the online classes offered in fall 2020 which represent a challenge for both instructors and students.

- The comparison of CLOs attainment for two consecutive semesters in fall 2019 and spring 2020 for all students enrolled in COE in GENG 215 course indicates that the most affected course learning outcome is CLO\#6 which deals mainly with the application of the design process. This drawback is mainly due to the sudden decision taken by the UAE University administration to carry on the rest of the spring semester from mid of March to the end of May using online teaching. The students and instructors were not that prepared to tackle different situations, opportunities, and problems associated with the online scenario.

As future work, this initial study should be extended to other courses taught in COE at UAEU with more focus on the new tools that should be implemented in online teaching and assessment methods for each course and more attention should be given to courses with a design component.

\section{REFERENCES}

ABET (2021). Retrieved from https://www.abet.org/

Banta, T.W. (2004). Developing assessment methods at classrooms, unit, and university-wide levels. Assessment workshop series - No 4. Retrieved from https://www.academia.edu/161594/Developing_a_variety_of_assessment_methods

Banta, T.W and Palomba, C.A. (2015). Assessment Essentials: Planning, Implementing, and Improving Assessment in higher Education ( $2^{\text {nd }}$ Ed.). San Francisco, CA: Jossey-Bass.

College of Engineering Last updated: Dec 9, 2018. Retrieved from

https://eng.uaeu.ac.ae/en/about/index.shtml

Colleges of United Arab Emirates University. Last updated: Feb 16, 2021. Retrieved from https://www.uaeu.ac.ae/en/colleges.shtml

Engineering Requirement Unit. Last updated: Dec 21, 2020. Retrieved from

https://eng.uaeu.ac.ae/en/departments/eru/about.shtml

ERU Courses. last updated: June 27, 2021. https://eng.uaeu.ac.ae/en/departments/eru/courses.shtml Fort, A. O. (2011). Learning about learning. Liberal Education, (winter) 56-60. 
Huffman, L., Adamapoulos, A., Merdock, G., Cole, A. and McDermid, R. (2011). Strategies to motivate students for program assessment. Educational Assessment, 16, 90-103.

Liu, O. L., Bridgeman, B. and Adler, R. M. (2012). Measuring learning outcomes in higher education: Motivation matters. Educational Researcher, 41(9), 352-362.

Luce, C. and Kirman, J.P. (2016). Using Indirect vs. Direct Measures in the Summative Assessment of Student Learning in Higher Education. Journal of the Scholarship of Teaching and Learning, 16(4), pp. 75-91. https://doi.org/10.14434/josotl.v16i4.19371

Martell, K. (2007). Assessing student learning: Are business schools making the grade? Journal of Education for Business, 82(4), 189-195.

Pederson, D.E and White, F. (2011). Using a Value-added Approach to assess the Sociology Major. Teaching Sociology, 39(2), 138-149. https://doi.org/10.1177/0092055X11400437

Price, B.A and Randall, C.H. (2008). Assessing Learning Outcomes in Quantitative Courses: Using Embedded Questions for Direct Assessment. Journal of Education for Business, 83(5), 288294. https://doi.org/10.3200/JOEB.83.5.288-294

Suskie, L. (2009). Assessing Student Learning: A common Sense Guide (2 ${ }^{\text {nd }}$ Ed.). San Francisco, CA: Jossey-Bass. 